\title{
Analisa Limbah Fosfor Kegiatan Keramba Jaring Apung di Danau Laut Tawar Aceh Tengah
}

\author{
Saiful Adhar ${ }^{*}$, Rachmawati Rusydi $^{2}$, Mainisa $^{3}$, Erlangga $^{4}$, Munawwar Khalil $^{5}$, Eva $_{\text {Ayuzar }}{ }^{6}$ \\ 1,2,3,5,6Program Studi Akuakultur, Fakultas Pertanian, Universitas Malikussaleh \\ ${ }^{4}$ Program Studi Ilmu Kelautan, Fakultas Pertanian, Universitas Malikussaleh \\ Jalan Cot Teungku Nie, Kampus Utama Reuleut, Muara Batu, Aceh Utara \\ * Koresponden email : saifuladhar@unimal.ac.id
}

Diterima: 10 Juni 2021

Disetujui: 22 Juni 2021

\begin{abstract}
Floating net cage activities can cause water quality to decrease. The feed remains and the metabolism of the fish from these activities produces nitrogen and phosphorus. The objective of this study is to obtain the calculation model and the amount of phosphorus released into the waters of Laut Tawar Lake as a result of floating cage activities. The resulting formula was $\mathrm{Pw}=(\mathrm{F} \times[\mathrm{P}] \mathrm{p})-((\mathrm{It}-\mathrm{Io}) \times[\mathrm{P}] \mathrm{i})$, where their variables were given feed $(\mathrm{F})$, phosphorus concentration of feed $([\mathrm{P}] \mathrm{p})$, the final weight of fish (It), the initial weight of fish (Io), and phosphorus concentration in fishes ([P]i). It can be used to predict the increase in phosphorus waste based on the increase in floating net cage area. The weight of tilapia increases exponentially with the day of cultivation in the equation $\mathrm{Y}=12.70 \mathrm{e}^{0.02 \mathrm{x}}$ and the goldfish followed the formula $\mathrm{Y}=2.28 \mathrm{e}^{0.03 x}$. Phosphorus in tilapia varies from $1.58 \%$ to $2.23 \%$ with an average of $1.97 \%$. Goldfish contain $1.19-2.02 \%$ phosphorus, with an average of $1.52 \%$. Goldfish growth was not optimal due to inadequate feeding, so without excessive feeding and did not generate phosphorus waste. The cultivation of tilapia releases $0.09 \mathrm{Kg} \mathrm{P} / \mathrm{m}^{2}$ of phosphorus waste from floating cages .
\end{abstract}

Keywords: eutrophication, feed, tilapia, goldfish, nutrients

\begin{abstract}
Abstrak
Kegiatan keramba jaring apung berpotensi menimbulkan penurunan kualitas perairan. Sisa pakan dan metabolisme ikan dari kegiatan tersebut menghasilkan nutrien nitrogen dan fosfor. Penelitian ini bertujuan untuk memperoleh model perhitungan dan jumlah fosfor yang dilepaskan ke perairan Danau Laut Tawar dari kegiatan keramba jaring apung. Persamaan yang diperoleh $\mathrm{Pw}=(\mathrm{F} \times[\mathrm{P}] \mathrm{p})-((\mathrm{It}-\mathrm{Io}) \mathrm{x}[\mathrm{P}] \mathrm{i})$ dengan variabel pakan yang diberikan (F), konsentrasi fosfor pakan ([P]p), bobot akhir ikan (It), bobot awal ikan (Io), dan konsentrasi fosfor dalam ikan ([P]i). Hasil perhitungan dapat digunakan untuk memprediksi peningkatan limbah fosfor berdasarkan peningkatan luas areal KJA. Bobot ikan nila meningkat secara exponensial dengan hari pemeliharaan mengikuti persamaan $\mathrm{Y}=12.70 \mathrm{e}^{0.02 \mathrm{x}}$ dan ikan mas mengikuti persamaan $\mathrm{Y}=2.28 \mathrm{e}^{0.03 \mathrm{x}}$. Fosfor dalam tubuh ikan nila berkisar $1,58-2,23 \%$ dengan rata-rata $1,97 \%$. Tubuh ikan mas mengandung fosfor antara 1,19 - 2,02 \% dengan rata-rata 1,52\%. Pengamatan menunjukkan pertumbuhan ikan mas tidak optimal disebabkan pemberian pakan yang tidak sesuai, sehingga tanpa kelebihan pakan dan tidak menghasilkan limbah fosfor. Budidaya ikan nila melepaskan limbah fosfor sebesar $0,09 \mathrm{Kg} \mathrm{P} / \mathrm{m}^{2}$ dari KJA.
\end{abstract}

Kata Kunci: eutrofikasi, pakan, ikan nila, ikan mas. nutrient

\section{Pendahuluan}

Kegiatan keramba jaring apung adalah kegiatan budidaya perikanan secara intensif dengan menggunakan wadah jaring apung yang ditempatkan di badan air dalam. Kegiatan budidaya ini menggunakan pakan komersial dalam proses pembesaran ikan. Usaha budidaya ini terus meningkat dari waktu ke waktu mengikuti permintaan kebutuhan ikan air tawar yang semakin meningkat. Peningkatan kebutuhan ikan air tawar menyebabkan peningkatan upaya budidaya ikan secara intensif yang dikembangkan dengan keramba jaring apung (KJA). Hal ini menyebabkan semakin meluasnya jumlah KJA di perairan Danau Laut Tawar, Aceh Tengah.

Danau Laut Tawar merupakan salah satu danau terbesar di Provinsi Aceh yang memiliki peran penting secara ekologi, ekonomi, kesehatan dan estetika. Danau ini memiliki beberapa spesies ikan endemic, diantaranya ikan depik (R. tawarensis) dan ikan kawan (P. tawarensis) [1]. Keberadaan sejumlah biota perairan, terutama ikan, menjadi sumber penghasilan bagi masyarakat sekitar yang berprofesi sebagai 
nelayan tangkap. Selain usaha perikanan tangkap, masyarakat di sekitar Danau Laut Tawar juga memanfaatkan perairan danau untuk mengembangkan usaha budidaya ikan dengan KJA [2]. Masyarakat Kota Takengon menggunakan air minum yang bersumber dari Danau Laut Tawar. Secara estetika keindahan alam kawasan Danau Laut Tawar merupakan daya tarik pariwisata.

Peningkatan areal KJA di perairan Danau Laut Tawar berpotensi menimbulkan dampak buruk terhadap kualitas perairan danau tersebut. Penurunan kualitas perairan oleh aktivitas KJA disebabkan oleh beban limbah sisa kegiatan KJA [3, 4, 5]. Limbah aktivitas kegiatan KJA berupa sisa pakan yang tidak dikonsumsi dan sisa hasil metabolisme ikan $[6,7]$ berupa feses dan urine. Sisa pakan dari KJA mengandung nitrogen $(\mathrm{N})$ dan fosfor $(\mathrm{P})$ merupakan faktor utama polusi budidaya perairan $[3,8]$, begitu juga dengan feses dan urin merupakan sumber $\mathrm{N}$ dan $\mathrm{P}$ dari KJA [5].

Keberadaan senyawa $\mathrm{N}$ dan $\mathrm{P}$ ini secara berlebihan di perairan danau mendorong tumbuhnya fitoplankton secara berlebihan [5], sehingga menimbulkan eutrofikasi [9] di perairan danau. Eutrofikasi merupakan proses pengayaan nutrien oleh peningkatan unsur hara yang melampaui batas di ekosistem air $[10,11]$ dan proses penumpukan nutrien, organik, dan sedimen yang mendorong penuaan alami danau [12]. Selama beberapa dekade ini eutrofikasi telah menjadi isu utama sebagai salah satu penyebab kerusakan lingkungan perairan [13].

Eutrofikasi merupakan salah satu penyebab utama degradasi ekosistem danau [14, 15] yang berkonsekuensi pada penurunan daya dukung dan fungsi danau [16]. Eutrofikasi berdampak mempercepat produktivitas biologi yang ditandai dengan meningkatnya biomassa algae [17]. Selain itu eutrofikasi juga menyebabkan perubahan proses biogeokimia, penurunan kecerahan air, penurunan oksigen terlarut, peningkatan partikel tersuspensi, peningkatan produksi $\mathrm{CO}_{2}$, asidifikasi perairan, anoksia sedimen, dan akumulasi $\mathrm{H}_{2} \mathrm{~S}[18,19]$.

Eutrofikasi perairan disebabkan oleh peningkatan nutrien, berupa dua nutrien utama yaitu $\mathrm{N}$ dan $\mathrm{P}$ $[20,21]$. Namun di perairan tawar, nutrien $P$ memegang peranan penting sebagai nutrien pembatas pertumbuhan fitoplankton [22, 23]. Maka pembahasan penyebab eutrofikasi di perairan Danau Laut Tawar difokuskan pada sumber dan jumlah nutrien P. Sejumlah nutrien P yang terkandung dalam pakan tidak semuanya terentensi dalam tubuh ikan yang dibudidaya [3]. Sisa nutrien $\mathrm{P}$ akan terbuang sebagai limbah kegiatan KJA ke sistem perairan. Jumlah limbah P dari kegiatan KJA merupakan selisih antara nutrien $\mathrm{P}$ dalam pakan yang diberikan dan nutrien $\mathrm{P}$ yang ter-retensi di dalam tubuh ikan.

Potensi peningkatan limbah P dari KJA di Danau Laut Tawar ditentukan oleh jumlah pakan yang diberikan dan banyak petakan KJA. Semakin luas areal KJA berarti semakin banyak jumlah ikan yang dibudidaya, sehingga jumlah pakan yang digunakan semakin tinggi. Hal ini akan berkonsekuensi pada semakin besar jumlah limbah P yang dihasilkan. Kondisi ini akan mengancam kelestarian Danau Laut Tawar, baik secara ekologis, ekonomi, estetika, maupun kesehatan manusia. Untuk menjaga keseimbangan ekosistem Danau Laut Tawar dan keberlanjutan aktivitas perekonomian pembudidaya KJA, dibutuhkan informasi ilmiah tentang jumlah limbah fosfor yang dihasilkan dari aktivitas KJA. Hal itu diperlukan sebagai dasar kebijakan penataan KJA dan pengelolaan Danau Laut Tawar.

Aktivitas KJA mengakibatkan pelepasan sejumlah sisa pakan yang mengandung senyawa $\mathrm{P}$ ke perairan. Limbah $\mathrm{P}$ ini menyebabkan peningkatan nutrien $\mathrm{P}$ perairan, yang berpotensi timbulnya eutrofikasi yang berujung pada penurunan kualitas air danau. Maka perlu diketahui berapa jumlah beban $\mathrm{P}$ yang dilepaskan ke perairan dari aktivitas KJA di Danau Laut Tawar. Jumlah beban P yang terlepas ke perairan dapat diketahui berdasarkan kandungan $\mathrm{P}$ dalam pakan, jumlah pakan, jumlah produksi, dan kandungan $\mathrm{P}$ dalam tubuh ikan budidaya. Penelitian ini bertujuan untuk memperoleh model perhitungan limbah fosfor kegiatan KJA dan untuk mengetahui jumlah limbah fosfor $(\mathrm{P})$ per satuan luas keramba jaring apung yang dilepaskan ke perairan Danau Laut Tawar.

\section{Metode Penelitian}

Penelitian ini dilaksanakan di kawasan Danau Laut Tawar, Kabupaten Aceh Tengah yang meliputi Kecamatan Lut Tawar dan Kebayakan. Lokasi pengambilan data dilaksanakan di sentra-sentra budidaya keramba jaring apung, yaitu One-one, Toweren, dan Kebayakan. Pelaksanaan penelitian dilakukan pada bulan Agustus sampai Oktober 2020. 


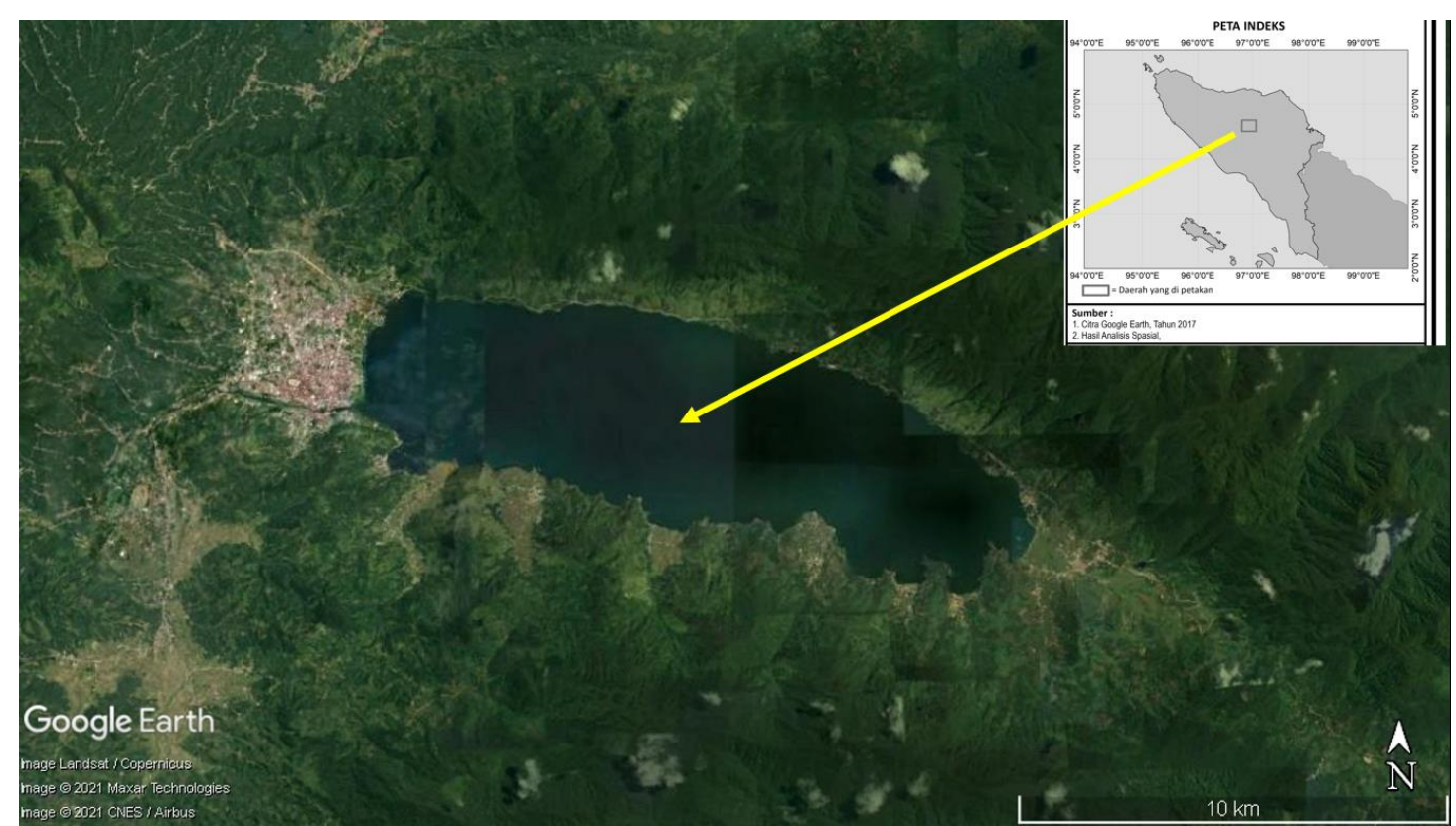

Gambar 1. Lokasi penelitian

Sumber: Google Earth (2021)

Penelitian ini menggunakan data primer yang diperoleh berdasarkan observasi dan wawancara di lokasi penelitian dan analisis laboratorium terhadap sampel ikan dan pakan. Jenis dan metode pengumpulan data disajikan pada Tabel 1.

Tabel 1. Jenis data dan metode pengumpulan data

\begin{tabular}{clcc}
\hline No & \multicolumn{1}{c}{ Parameter } & Jenis Data & Metode \\
\hline 1. & Luas petakan KJA & primer & Survei/wawancara \\
2. & Jumlah/bobot benih & primer & Survei/wawancara \\
3. & Jumlah/bobot hasil panen & primer & Survei/wawancara \\
4. & Waktu pemeliharaan sampai panen & primer & Survei/wawancara \\
5. & Jumlah pakan yang digunakan & primer & Survei/wawancara \\
6. & Konsentrasi P pakan & primer & analisis laboratorium \\
7. & Konsentrasi P ikan budidaya & primer & analisis laboratorium \\
\hline
\end{tabular}

Perhitungan jumlah beban P yang terbuang ke perairan dilakukan berdasarkan hukum kekekalan massa. Jumlah P yang menjadi limbah adalah selisih P dalam pakan dan P dalam tubuh ikan. Diasumsikan selama pemeliharaan nutrisi ikan hanya bersumber dari pakan yang diberikan. Sejumlah P yang tidak terretensi di dalam tubuh ikan merupakan limbah $\mathrm{P}$ sisa kegiatan budidaya KJA. Secara matematis dapat dinyatakan dengan persamaan :

$$
\mathrm{Pw}=\mathrm{Pp}-\mathrm{Pi}
$$

Dimana $\mathrm{Pw}=$ jumlah limbah $\mathrm{P}$ sisa kegiatan $\mathrm{KJA}\left(\mathrm{Kg} \mathrm{P} / \mathrm{m}^{2}\right)$

$\mathrm{Pp}=$ jumlah $\mathrm{P}$ dalam pakan $\mathrm{KJA}\left(\mathrm{Kg} \mathrm{P} / \mathrm{m}^{2}\right)$

$\mathrm{Pi}=$ jumlah $\mathrm{P}$ dalam tubuh ikan budidaya $\left(\mathrm{Kg} \mathrm{P} / \mathrm{m}^{2}\right)$

Jumlah fosfor dalam pakan (Pp) diketahui berdasarkan jumlah pakan yang diberikan selama pemeliharaan dan kadar P dalam pakan. Secara matematis dinyatakan dengan persamaan :

$$
\mathrm{Pp}=\mathrm{F} \times[\mathrm{P}] \mathrm{p}
$$

Dimana Pp $=$ jumlah $\mathrm{P}$ dalam pakan $\mathrm{KJA}\left(\mathrm{Kg} \mathrm{P} / \mathrm{m}^{2}\right)$

$\mathrm{F} \quad=$ jumlah pakan yang diberikan selama pemeliharaan $\left(\mathrm{Kg} / \mathrm{m}^{2}\right)$

$[\mathrm{P}] \mathrm{p}=$ konsentrasi $\mathrm{P}$ dalam pakan $(\%)$ 
Jumlah $\mathrm{P}$ dalam tubuh ikan yang ter-retensi selama pemeliharaan diketahui berdasarkan jumlah peningkatan bobot ikan selama pemeliharaan dan konsentrasi $\mathrm{P}$ dalam tubuh ikan. Persamaan matematis pernyataan tersebut adalah :

$$
\mathrm{Pi}=\mathrm{I} x[\mathrm{P}] \mathrm{i}
$$

Dimana Pi $=$ jumlah $\mathrm{P}$ dalam tubuh ikan $\left(\mathrm{Kg} \mathrm{P} / \mathrm{m}^{2}\right)$

$\mathrm{I}=$ peningkatan bobot ikan selama pemeliharaan $\left(\mathrm{Kg} / \mathrm{m}^{2}\right)$

$[\mathrm{P}] \mathrm{i}=$ konsentrasi $\mathrm{P}$ dalam tubuh ikan $(\%)$

Peningkatan bobot ikan selama masa pemeliharaan diperoleh dari selisih antara bobot ikan di akhir masa pemeliharaan dan bobot benih ikan yang ditebar di awal pemeliharaan. Secara matematis dirumuskan dengan persamaan :

$$
\mathrm{I}=\mathrm{It}-\mathrm{Io} \text {. }
$$

Dimana I = peningkatan bobot ikan selama pemeliharaan $\left(\mathrm{Kg} / \mathrm{m}^{2}\right)$

It $=$ bobot ikan di akhir masa pemeliharaan $\left(\mathrm{Kg} / \mathrm{m}^{2}\right)$

Io = bobot ikan di awal masa pemeliharaan $\left(\mathrm{Kg} / \mathrm{m}^{2}\right)$

Untuk memperoleh data bobot benih, bobot ikan waktu panen, jumlah pakan, dan waktu pemeliharaan dilakukan survei di lokasi penelitian dan wawancara dengan para pembudidaya, sehingga diperoleh data rata-rata menurut luas petakan KJA. Data hasil survei dan wawancara tersebut ditabulasi dan dihitung nilai rata-rata. Nilai rata-rata tersebut diasumsikan sebagai data kegiatan KJA di perairan Danau Laut Tawar yang digunakan dalam perhitungan. Nilai konsentrasi P dalam pakan dan tubuh ikan diperoleh dari hasil analisis laboratorium. Sampel ikan diambil dari KJA menurut umur pemeliharaan dari masing-masing jenis ikan yang dibudidaya. Jenis pakan yang digunakan oleh pembudidaya di KJA dianalisis kadar P di laboratorium.

\section{Hasil dan Pembahasan}

Areal budidaya ikan keramba jaring apung (KJA) di Danau Laut Tawar yang diamati mencakup 13 unit KJA yang terdiri dari 106 petakan dengan mewawancarai 11 orang responden. Lokasi tersebut berada di kawasan perairan One-one sebanyak 7 unit KJA, Toweren sebanyak 4 unit KJA, dan Kebayakan sebanyak 2 unit KJA. Total areal pengamatan seluas $2293 \mathrm{~m}^{2}$ dengan perincian di One-one sebesar 60,93 persen, Toweren sebesar 16, 83 persen, dan Kebayakan sebesar 22,24 persen.

Ikan yang dibudidaya di lokasi pengamatan terdiri dari 2 jenis, yaitu ikan nila (Oreochromis niloticus) dan ikan mas (Cyprinus carpio). Luas areal pemeliharaan ikan nila mendominasi areal pengamatan yang mencapai sebesar 92,28 persen (98 petakan), sedang luas areal budidaya ikan mas hanya sebesar 7,72 persen. Ukuran petakan KJA yang digunakan oleh pembudidaya di kawasan Danau Laut

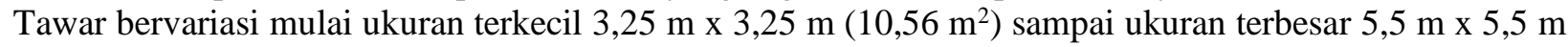
$\left(30,25 \mathrm{~m}^{2}\right)$. Data ukuran dan jumlah petakan KJA yang diamati disajikan pada Tabel 2.

Tabel 2. Ukuran, jumlah, dan luas petakan KJA pengamatan di Danau Laut Tawar

\begin{tabular}{lcrrr}
\hline Ukuran & $\begin{array}{c}\text { Luas } \\
\left(\mathrm{m}^{2}\right)\end{array}$ & Jumlah & $\begin{array}{c}\text { Total Luas } \\
\left(\mathrm{m}^{2}\right)\end{array}$ & Persen \\
\hline $3.25 \mathrm{~m}$ x 3.25 m & 10.56 & 2 & 21.13 & 0.92 \\
$3 \mathrm{~m} \mathrm{x} \mathrm{4} \mathrm{m}$ & 12.00 & 14 & 168.00 & 7.33 \\
$3.5 \mathrm{~m} \mathrm{x} \mathrm{4.5} \mathrm{m}$ & 15.75 & 10 & 157.50 & 6.87 \\
$4 \mathrm{~m}$ x 5 m & 20.00 & 20 & 400.00 & 17.44 \\
$5 \mathrm{~m}$ x 5 m & 25.00 & 42 & 1050.00 & 45.79 \\
$4.5 \mathrm{~m}$ x 6.5 m & 29.25 & 4 & 117.00 & 5.10 \\
$3.8 \mathrm{~m}$ x 7 m & 26.60 & 12 & 319.20 & 13.92 \\
$5.5 \mathrm{~m}$ x 5.5 m & 30.25 & 2 & 60.50 & 2.64 \\
\hline Jumlah & \multicolumn{5}{c}{2293.33} & 100.00 \\
\hline Rata-rata & 21,64 & 106 & \\
\hline
\end{tabular}

Sumber : Observasi (2020) 
Data pengamatan yang disajikan pada Tabel 2 menunjukkan bahwa ukuran petakan $5 \mathrm{~m}$ x $5 \mathrm{~m}$ merupakan petakan KJA yang dominan ditemukan di kawasan budidaya KJA Danau Laut Tawar. Berdasarkan data total luas areal pengamatan dan total jumlah petakan pengamatan, maka diketahui luas petakan rata-rata petakan KJA di kawasan Danau Laut Tawar adalah sebesar 21,64 m².

Penebaran benih ikan nila di KJA Danau Laut Tawar dilakukan oleh pembudidaya berkisar antara 5000 - 10000 ekor/petak menurut luas petakan KJA. Hasil observasi menunjukkan bahwa padat tebar benih ikan nila di KJA Danau Laut Tawar berkisar antara $250-500 \mathrm{ekor} / \mathrm{m}^{2}$. Berdasarkan total luas dan jumlah petakan KJA budidaya ikan nila diperoleh nilai rata-rata padat tebar benih sebesar $384 \mathrm{ekor} / \mathrm{m}^{2}$. Padat tebar benih ikan mas di KJA Danau Laut Tawar berkisar antara $75-120 \mathrm{ekor} / \mathrm{m}^{2}$. Nilai rata-rata padat tebar ikan mas diperoleh sebesar $109 \mathrm{ekor} / \mathrm{m}^{2}$.

Untuk mendapatkan data yang representatif kegiatan KJA di Danau Laut Tawar, maka seluruh data hasil observasi pada masing-masing KJA dikonversi ke nilai satuan luas. Hal ini dilakukan untuk memudahkan perhitungan mengingat data luas KJA yang bervariasi di lapangan. Nilai data jumlah pakan, hasil panen, dan beban fosfor dihitung dalam satuan per meter luas $\left(\mathrm{m}^{2}\right)$.

Waktu pemeliharaan ikan nila di KJA Danau Laut Tawar berkisar antara 150 - 180 hari. Hal tersebut sangat dipengaruhi oleh kondisi permintaan pasar. Rata-rata waktu pemeliharaan diperoleh sebesar 155 hari. Bobot ikan nila pada waktu panen berkisar antara $0,25-0.33 \mathrm{Kg} / \mathrm{ekor}$, dengan nilai rata-rata 0,29 $\mathrm{Kg} / \mathrm{ekor}$. Hasil panen ikan nila yang diperoleh berkisar antara $29,75-66,67 \mathrm{Kg} / \mathrm{m}^{2}$, dengan nilai rata-rata sebesar $43,51 \mathrm{Kg} / \mathrm{m}^{2}$. Bobot awal ikan nila diperoleh berdasarkan jumlah padat tebar rata-rata dan bobot benih yang ditebar. Berdasarkan data wawancara dan pengamatan diketahui bahwa benih ikan nila yang digunakan pada semua KJA memiliki bobot yang seragam, yaitu seberat 4 g/ekor. Maka diperoleh total bobot awal ikan nila sebesar $1,54 \mathrm{Kg} / \mathrm{m}^{2}$.

Ikan mas di KJA Danau Laut Tawar dipelihara selama 180 hari, dengan bobot saat panen sebesar 1 Kg/ekor. Data wawancara menunjukkan bahwa jumlah panen ikan mas di KJA Danau Laut Tawar berkisar antara $33,33-83,33 \mathrm{Kg} / \mathrm{m}^{2}$, dengan rata-rata $59,89 \mathrm{Kg} / \mathrm{m}^{2}$. Bobot benih ikan mas yang digunakan di $\mathrm{KJA}$ Danau Laut Tawar berkisar antara 2 - 3 g/ekor, dengan bobot rata-rata seberat 2,81 g/ekor. Berdasarkan nilai tersebut dan data jumlah padat tebar benih maka diperoleh bobot awal ikan mas adalah sebesar 0,31 $\mathrm{Kg} / \mathrm{m}^{2}$.

Analisa kadar P dalam tubuh ikan nila dilakukan pada 15 sampel yang diambil menurut usia ikan. Usia sampel ikan berkisar antara 40 - 180 hari. Hasil analisa kadar P dalam tubuh ikan nila menunjukkan nilai yang berkisar antara $1,58-2,23 \%$, dengan nilai rata-rata sebesar $1,97 \%$. Kadar P dalam tubuh ikan mas dianalisa pada 12 sampel. Usia ikan mas berkisar antara $90-200$ hari, dan kadar P dalam tubuh ikan mas berkisar antara 1,19-2,02\% dengan nilai rata-rata $1,52 \%$.

Usaha budidaya ikan di KJA Danau Laut Tawar menggunakan pakan sebanyak 7 jenis. Pakan tersebut memiliki kandungan $\mathrm{P}$ yang berkisar antara 1,02 - 1,84\% bobot. Hasil analisa laboratorium terhadap 7 jenis pakan tersebut disajikan pada Tabel 3.

Tabel 3. Kadar fosfor dalam pakan KJA Danau Laut Tawar

\begin{tabular}{lccccccc}
\hline Jenis Pakan & P1 & P2 & P3 & P4 & P5 & P6 & P7 \\
\hline Fosfor $(\%)$ & 1.49 & 1.02 & 1.43 & 1.25 & 1.84 & 1.14 & 1.38 \\
\hline \multicolumn{7}{l}{ Sumber : Analisa laboratorium $(2020)$}
\end{tabular}

Jumlah pemberian pakan ikan nila di KJA Danau Laut Tawar diobservasi pada 83 petakan dengan total luas areal $1834 \mathrm{~m}^{2}$. Hasil perhitungan jumlah pakan yang digunakan menurut umur ikan diilustrasikan pada Gambar 2. Gambar 2 menjelaskan bahwa jika pemeliharaan ikan nila dilakukan sampai 180 hari, maka akan menghabiskan pakan sebanyak $76,81 \mathrm{Kg} / \mathrm{m}^{2}$, dengan rata-rata pemberian pakan sebesar 0,43 $\mathrm{Kg} / \mathrm{hari} / \mathrm{m}^{2}$. Namun hasil observasi di KJA Danau Laut Tawar rata-rata masa pemeliharaan ikan nila selama 155 hari, sehingga pakan yang digunakan sebanyak $62,99 \mathrm{Kg} / \mathrm{m}^{2}$. Adapun pemberian pakan yang dilakukan untuk ikan nila setelah 150 hari adalah data yang diperoleh jika ikan tersebut belum dipanen karena belum adanya permintaan pasar. 


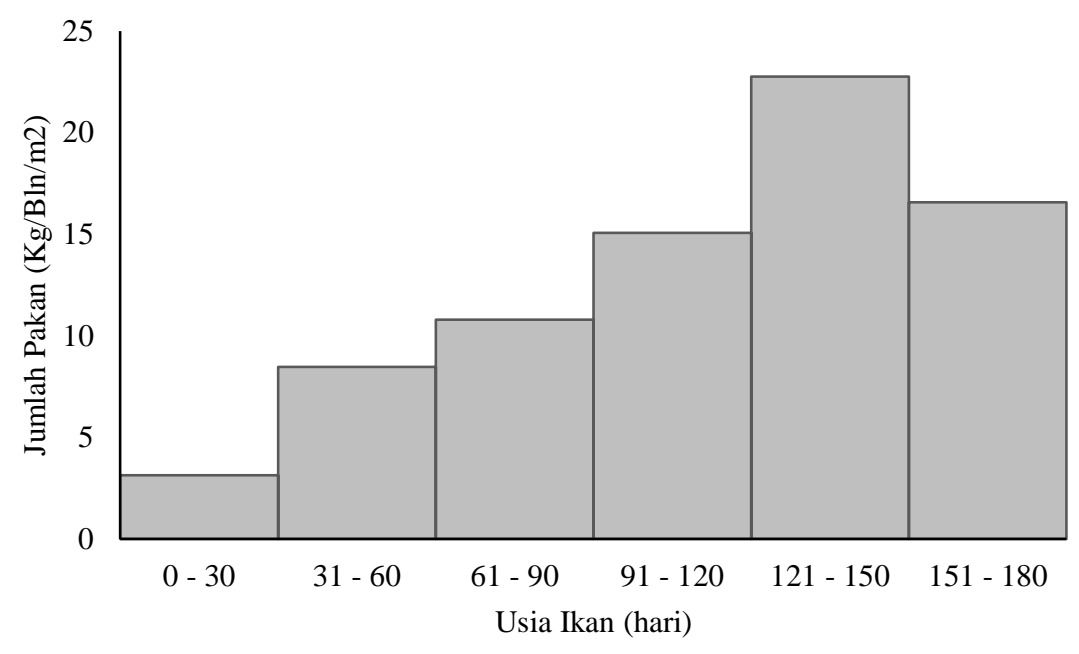

Gambar 2. Jumlah pemberian pakan Ikan Nila di KJA Danau Laut Tawar

Pembudidaya ikan nila di KJA Danau Laut Tawar menggunakan jenis pakan P1, P2, P3, P4, P5, P6, dan P7 dengan luas areal budidaya yang berbeda. Nilai rata-rata kadar P dalam pakan untuk budidaya ikan nila di KJA Danau Laut Tawar diperoleh berdasarkan nilai persentase kadar P dan luas areal penggunaan jenis pakan. Perhitungan tersebut memberikan nilai rata-rata kadar P dalam pakan ikan nila sebesar 1,39\%.

Jumlah pakan ikan mas yang digunakan di KJA Danau Laut Tawar diobservasi pada 8 petakan dengan total luas areal $177 \mathrm{~m}^{2}$. Total penggunaan pakan ikan mas di KJA Danau Laut Tawar selama 180 hari adalah $67,79 \mathrm{Kg} / \mathrm{m}^{2}$. Jumlah pakan ikan mas yang digunakan menurut umur ikan budidaya diilustrasikan pada Gambar 3.

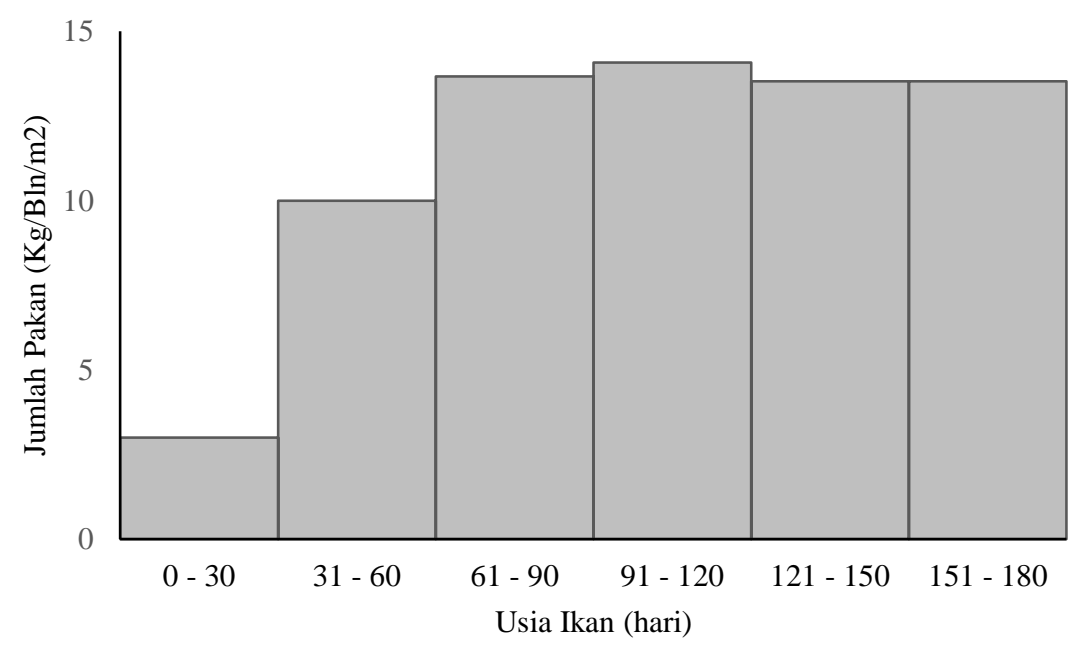

Gambar 3. Jumlah pemberian pakan Ikan Mas di KJA Danau Laut Tawar

Budidaya ikan mas menggunakan pakan jenis $\mathrm{P} 4$ dan P6 pada luas areal $177 \mathrm{~m}^{2}$ dalam 8 petakan dengan ukuran yang berbeda. Nilai rata-rata persentase kadar P dalam pakan ikan mas adalah sebesar 1,22 $\%$. Nilai ini diperoleh berdasarkan luas areal penggunaan jenis pakan di lokasi penelitian, dimana terdapat perbedaan luas areal budidaya ikan mas menurut masing-masing responden. Rata-rata persentase kadar $\mathrm{P}$ pakan ikan mas tersebut digunakan untuk menghitung jumlah unsur fosfor $(\mathrm{P})$ dalam pakan ikan mas di KJA Danau Laut Tawar.

Proses fisiologis tubuh organisme berhubungan langsung dengan ketersediaan mineral fosfor $(\mathrm{P})$. Ikan membutuhkan mineral fosfor untuk pertumbuhan dan pembentukan tulang [24]. Peningkatan bobot ikan diikuti oleh peningkatan kandungan senyawa fosfor dalam tubuhnya, yang menunjukkan bahwa mineral fosfor berpengaruh terhadap pertumbuhan ikan [25]. Pertumbuhan ikan nila dan ikan mas yang dibudidaya di KJA Danau Laut Tawar mengikuti usia ikan. Hubungan yang sangat erat terlihat pada hubungan usia dan bobot ikan di KJA Danau Laut Tawar ditampilkan pada Gambar 4. 


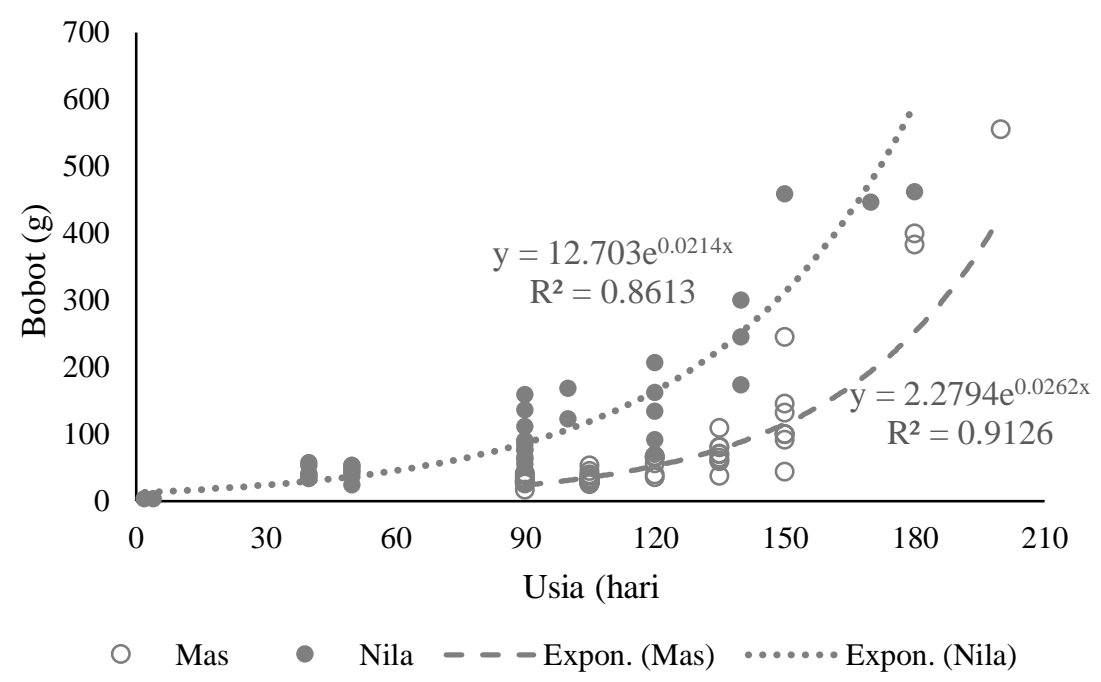

Gambar 4. Hubungan usia dan bobot ikan di KJA Danau Laut Tawar

Ilustrasi grafis yang disajikan pada Gambar 4 menunjukkan bahwa peningkatan usia ikan diikuti oleh peningkatan bobot ikan secara eksponensial. Hal ini juga menunjukkan terjadi peningkatan jumlah kandungan senyawa fosfor $(\mathrm{P})$ di dalam tubuh ikan secara eksponensial mengikuti pertambahan usia ikan. Sehingga nilai persentase nilai kadar $\mathrm{P}$ rata-rata dapat digunakan untuk menentukan jumlah kadar $\mathrm{P}$ dalam tubuh ikan. Gambar 4 juga menunjukkan bobot ikan mas lebih kecil dibandingkan dengan ikan nila dengan usia yang sama. Hal ini diduga karena jumlah pemberian pakan yang tidak sesuai dengan kebutuhan ikan mas sehingga mengakibatkan pertumbuhan ikan mas di KJA Danau Laut Tawar tidak optimal. Dugaan tersebut didasarkan pada fakta bahwa jumlah pakan ikan mas tidak mengalami peningkatan yang signifikan mulai hari ke-91 sampai hari ke-180 seperti ditunjukkan pada Gambar 3. Hal itu tidak sesuai jika dibandingkan dengan bobot ikan mas yang semakin meningkat, sehingga diasumsikan ikan mas lebih banyak menggunakan pakan alami yang terdapat di perairan untuk pertumbuhannya.

Di sisi lain kelebihan fosfor dalam pakan pada sistem KJA akan dikeluarkan ke media budidaya [6, 7], dimana akan menyebabkan penurunan kualitas air media budidaya [3, 4, 5]. Jumlah kelebihan fosfor pada sistem KJA Danau Laut Tawar dapat diketahui berdasarkan selisih jumlah fosfor yang diberikan yang terkandung dalam pakan dan jumlah fosfor yang tertinggal di tubuh ikan. Perhitungan jumlah fosfor yang masuk ke media budidaya sebagai limbah kegiatan KJA dihitung dengan menggunakan Persamaan 1.

Persamaan 1 tersebut terdiri dari komponen fosfor dalam pakan (Pp) dan fosfor dalam tubuh ikan (Pi). Perhitungan nilai Pp diperoleh dengan Persamaan 2 yang merupakan perkalian jumlah pakan yang diberikan dan konsentrasi fosfor dalam pakan ([P]p). Perhitungan nilai fosfor dalam tubuh ikan dilakukan dengan Persamaan 3 yang memiliki komponen peningkatan bobot ikan (I) dan konsentrasi fosfor dalam tubuh ikan ([P]i). Persamaan 2 dan Persamaan 3 disubstitusikan ke Persamaan 1, sehingga diperoleh Persamaan 5, yaitu :

$$
\mathrm{Pw}=(\mathrm{F} \times[\mathrm{P}] \mathrm{p})-(\mathrm{I} \times[\mathrm{P}] \mathrm{i})
$$

Dimana $\mathrm{Pw} \quad=$ jumlah limbah $\mathrm{P}$ sisa kegiatan $\mathrm{KJA}\left(\mathrm{Kg} \mathrm{P} / \mathrm{m}^{2}\right)$

$\mathrm{F} \quad=$ jumlah pakan yang diberikan selama pemeliharaan $\left(\mathrm{Kg} / \mathrm{m}^{2}\right)$

$[\mathrm{P}] \mathrm{p}=$ konsentrasi $\mathrm{P}$ dalam pakan $(\%)$

$\mathrm{I} \quad=$ peningkatan bobot ikan selama pemeliharaan $\left(\mathrm{Kg} / \mathrm{m}^{2}\right)$

$[\mathrm{P}] \mathrm{i}=$ konsentrasi $\mathrm{P}$ dalam tubuh ikan $(\%)$

Peningkatan bobot ikan (I) diperoleh dengan perhitungan yang menggunakan Persamaan 4, dimana merupakan selisih antara bobot akhir ikan (It) dan bobot awal ikan (Io). Persamaan 4 tersebut dapat disubstitusikan ke Persamaan 5, sehingga diperoleh persamaan baru berupa :

$$
\mathrm{Pw}=(\mathrm{F} \times[\mathrm{P}] \mathrm{p})-((\mathrm{It}-\mathrm{Io}) \mathrm{x}[\mathrm{P}] \mathrm{i})
$$

Berdasarkan Persamaan 6 tersebut maka dapat diketahui bahwa untuk mengetahui jumlah limbah fosfor dari kegiatan KJA diperlukan data-data berupa jumlah pakan yang diberikan (F), konsentrasi P dalam pakan ([P]p), bobot akhir ikan (It), bobot awal ikan (Io), dan konsentrasi P dalam tubuh ikan ([P]i). 
Perhitungan dalam penelitian ini dilakukan berdasarkan persatuan luas KJA, dimana dapat diperoleh nilai dalam per $1 \mathrm{~m}^{2}$. Model persamaan yang digunakan ini dapat digunakan untuk memprediksi jumlah limbah fosfor berdasarkan peningkatan luas KJA.

Jumlah limbah fosfor pada kegiatan KJA di Danau Laut Tawar dianalisis pada pemeliharaan ikan nila dan ikan mas. Jumlah pakan yang digunakan pada kegiatan KJA di Danau Laut Tawar untuk pemeliharaan ikan nila sebanyak $62,99 \mathrm{Kg} / \mathrm{m}^{2}$ dan ikan mas sebesar $67.79 \mathrm{Kg} / \mathrm{m}^{2}$. Berdasarkan jumlah pakan tersebut dan nilai konsentrasi $\mathrm{P}$ dalam pakan, maka diketahui bahwa jumlah nutrient $\mathrm{P}$ yang diberikan selama pemeliharaan ikan di KJA Danau Laut Tawar adalah sebesar $0,92 \mathrm{Kg} \mathrm{P} / \mathrm{m}^{2}$ untuk ikan nila dan 0,83 $\mathrm{Kg} \mathrm{P} / \mathrm{m}^{2}$ untuk ikan mas.

Ikan nila di KJA Danau Laut Tawar yang dipelihara selama 155 hari mengalami peningkatan bobot sebesar $41,97 \mathrm{Kg} / \mathrm{m}^{2}$ dengan kandungan $\mathrm{P}$ dalam tubuhnya sebesar $1,97 \%$. Hal ini menunjukkan bahwa selama masa pemeliharaan ikan nila menyerap nutrient $\mathrm{P}$ yang diberikan sebesar $0,83 \mathrm{Kg} \mathrm{P} / \mathrm{m}^{2}$. Jumlah fosfor yang diberikan selama pemeliharaan ikan nila adalah sebesar $0,92 \mathrm{Kg} \mathrm{P} / \mathrm{m}^{2}$. Hal ini menunjukkan jumlah fosfor yang tertinggal di dalam tubuh ikan nila hanya sebesar 90,22\% dari yang diberikan. Adapun sisa fosfor yang tidak diserap oleh ikan nila merupakan limbah yang keluar ke media pemeliharaan adalah sebesar $0,09 \mathrm{Kg} \mathrm{P} / \mathrm{m}^{2}$.

Bobot ikan mas di KJA Danau Laut Tawar meningkat $59,57 \mathrm{Kg} / \mathrm{m}^{2}$ dalam masa pemeliharaan selama 180 hari. Rata-rata konsentrasi $\mathrm{P}$ dalam tubuh ikan mas adalah sebesar 1,52 \%, berarti jumlah senyawa $\mathrm{P}$ dalam tubuh ikan mas selama masa pemeliharaan sekitar $0,91 \mathrm{Kg} \mathrm{P} / \mathrm{m}^{2}$. Berdasarkan jumlah pakan yang diberikan diketahui bahwa jumlah nutrient $P$ yang diberikan selama pemeliharaan $0,83 \mathrm{Kg} / \mathrm{m}^{2}$, yang menunjukkan bahwa ada sumber nutrient $\mathrm{P}$ lain yang masuk ke tubuh ikan selain dari pakan yang diberikan. Hal ini dapat diduga berasal dari lingkungan media pemeliharaan, berupa plankton. Tidak optimalnya pemberian pakan untuk ikan mas oleh pembudidaya KJA di Danau Laut Tawar pada siklus pemeliharaan ketika survei ini dilakukan diduga karena permintaan pasar untuk ikan mas menurun. Pemeliharaan ikan mas dilaksanakan seadanya saja, dimana pembudidaya melakukan penghematan penggunaan pakan dan lebih memfokuskan modal untuk pemeliharaan ikan nila.

\section{Kesimpulan}

Kajian penelitian ini menghasilkan model persamaan perhitungan limbah fosfor kegiatan KJA, yaitu $\mathrm{Pw}=(\mathrm{F} \times[\mathrm{P}] \mathrm{p})-((\mathrm{It}-\mathrm{Io}) \times[\mathrm{P}] \mathrm{i})$. Parameter yang digunakan untuk perhitungan tersebut berupa jumlah pakan yang diberikan (F), konsentrasi P dalam pakan ([P]p), bobot akhir ikan (It), bobot awal ikan (Io), dan konsentrasi P dalam tubuh ikan ([P]i). Hasil perhitungan persamaan tersebut dapat digunakan untuk memprediksi peningkatan jumlah limbah fosfor berdasarkan peningkatan luas KJA. Kegiatan KJA di Danau Laut Tawar menghasilkan limbah fosfor sebesar $0,09 \mathrm{Kg} \mathrm{P} / \mathrm{m}^{2} \mathrm{KJA}$ pada budidaya ikan nila. Budidaya ikan mas di KJA Danau Laut Tawar tidak menghasilkan limbah fosfor. Hal ini masih diragukan, karena pengambilan data pada siklus pemeliharaan ikan mas tidak memadai untuk suatu riset.

\section{Saran}

Perlu dilakukan survei lebih lanjut dalam waktu beberapa siklus pemeliharaan tentang proses pembudidayaan ikan pada kegiatan KJA di Danau Laut Tawar untuk memperoleh nilai parameter secara lebih valid dan representatif. Terutama pada budidaya ikan mas masih diperlukan data yang lebih banyak. Hal ini mengingat penelitian ini hanya mengambil data dalam rentang waktu satu siklus pemeliharaan.

\section{Referensi}

[1] Z. A. Muchlisin dan I. Hasri, "Karakteristik Biologi Ikan Dominan Danau Laut Tawar," dalam Pengelolaan Sumber Daya Perikanan Danau Laut Tawar Aceh Tengah, Takengon, Amafard Press, 2015, pp. 252 - 281.

[2] Indra, "Kajian Kondisi Perikanan di Danau Laut Tawar Aceh Tengah," Agrisep, pp. 62-69, 2015.

[3] I. Ardi, "Budidaya Ikan Sistem Keramba Jaring Apung Guna Menjaga Keberlanjutan Lingkungan Perairan Waduk Cirata," Media Akuakultur, pp. 23-29, 2013.

[4] A. Yalcuk, N. B. Pakdil dan O. Kantürer, "Investigation of the effects of fish farms in Bolu (Turkey) on aquatic pollution," IJAFR, p. 1-13, 2014.

[5] L. P. Astuti, A. L. S. Hendrawan dan Krismono, "Pengelolaan Kualitas Perairan Melalui Penerapan Budidaya Ikan Dalam Keramba Jaring Apung "SMART"," Jurnal Kebijakan Perikanan Indonesia, pp. 87-97, 2018.

[6] A. K. Amirkolaie, "Reduction in the environmental impact of waste discharged by fish farms through feed and feeding," Reviews in Aquaculture 3(1), pp. 19 - 26, 2011. 
[7] X. Wang, L. M. Olsen, K. I. Reitan dan Y. Olsen, "Discharge of nutrient wastes from salmon farms: environmental effects, and potential for integrated multi-trophic aquaculture," Aquaculture Environment Interactions, p. 267-283, 2012.

[8] M. d. A. B. Moraes, C. F. d. Carmo, Y. A. Tabata dan C. T. J. Mercante, "Daily mass balance of phosphorus and nitrogen in effluents of production sectors of trout farming system," Acta Limnologica Brasiliensia, vol. 27, no. 3, pp. 330-340, 2015.

[9] L. H. Sipaúba-Tavares, R. N. Millan dan A. Milstein, "Limnology of an integrated cage-pond aquaculture farm," Acta Limnologica Brasiliensia, vol. 28, no. el, 2016.

[10] E. Irianto, R. Triweko dan D. Yudianto, "Estimasi Dinamik Jangka Panjang Terhadap Kualitas Air Untuk Pengendalian Eutrofikasi Pada Waduk Jatiluhur," Jurnal Teknik Hidraulik, p. 1 - 16, 2012.

[11] D. A. Lemley dan J. B. Adams, "Eutrophication," dalam Encyclopedia of Ecology (Second Edition), Elsevier, 2019, pp. 86-90.

[12] A. A. Melcher, A Trophic State Analysis of Lakes in Yellowstone National Park. Thesis, Provo: Department of Civil and Environmental Engineering, Brigham Young University, 2013.

[13] C. Le, Y. Zha, Y. Li, D. Sun, H. Lu dan B. Yin, "Eutrophication of Lake Waters in China: Cost, Causes, and Control," Environmental Management, p. 662-668, 2010.

[14] A. Sadick, "Temporal Variation of Eutrophication Assessment of Lake Bosomtwe, Ghana," Journal of Environmental Research, Engineering and Management, pp. 45-53, 2016.

[15] B. Vincon-Leite dan C. Casenave, "Modelling eutrophication in lake ecosystem: A review," Science of the Total Environment, p. 2985-3001, 2019.

[16] T. J. Alexander, P. Vonlanthen dan O. Seehausen, "Does eutrophication-driven evolution change aquatic ecosystem?," Philosophical Transactions B, p. 373; 20160041, 2017.

[17] A. S. Piranti, Sudarmadji, S. Hadisusanto dan A. Maryono, "Distribusi Vertikal Nutrien dan Potensi Terjadinya Blooming Algae pada Musim Kemarau di Zona Lakustrin Waduk Mrica Banjarnegara," dalam Seminar Nasional Biologi 2010 Biodiversitas dan Bioteknologi Sumberdaya Akuatik, Purwokerto, 2010.

[18] E. W. Irianto dan R. W. Triweko, Eutrofikasi Waduk dan Danau: Permasalahan, Pemodelan dan Upaya Pengendalian, Jakarta: Yayasan Badan Penerbit Pekerjaan Umum PT Mediatama Saptakarya, 2014.

[19] M. M. Dorgham, "Effects of Eutrophication," dalam Eutrophication: Cause, Consequences and Control, London, Springer, 2014, pp. 29 - 44.

[20] M. N. Khan dan F. Mohammad, "Eutrophication: Challenges and Solutions," dalam Eutrophication: Causes, Consequences and Control Volume 2, Dordrecht, Heidelberg, London, New York, Springer Science+Business Media B.V, 2014, pp. 1-15.

[21] M. Ma, J. Jia, Y. Hu, J. Yang, Y. Lu, K. Shi dan Y. Gao, "Changes in chlorophyll a and its response to nitrogen and phosphorus characteristics over the past three decades in Poyang Lake, China," Ecohydrology, p. e2270, 2020.

[22] D. W. Schindler, "The dilemma of controlling cultural eutrophication of lakes," Proceedings the Royal Society B, p. 4322-4333, 2012.

[23] F. Xie, F. Wu, G. Liu, Y. Mu, C. Feng, H. Wang dan J. P. Giesy, "Removal of Phosphate from Eutrophic Lakes through Adsorption by in Situ Formation of Magnesium Hydroxide from Diatomite," Environmental Science \& Technology, p. 582-590, 2013.

[24] G. A. Morales, R. L. Azcuy, M. E. Casaretto, L. Márquez, A. J. Hernández, F. Gómez, W. Koppe dan A. Mereu, "Effect of different inorganic phosphorus sources on growth performance, digestibility, retention efficiency and discharge of nutrients in rainbow trout (Oncorhynchus mykiss)," Aquaculture, vol. 495, pp. 568-574, 2018.

[25] Zainuddin, "Pengaruh Calsium dan Fosfor terhadap Pertumbuhan, Efisiensi Pakan, Kandungan Mineral dan Komposisi Tubuh Juvenil Ikan Kerapu Macan (Epinephelus fuscoguttatus)," Jurnal Ilmu dan Teknologi Kelautan Tropis, vol. 2, no. 2, pp. 1 - 9, 2010. 